\title{
Characterization of Excited States in a Multiple-Resonance-Type Thermally Activated Delayed Fluorescence Molecule Using Time-resolved Infrared Spectroscopy
}

\author{
Yuushi Shimoda, ${ }^{1}$ Masaki Saigo, ${ }^{1}$ Tomohiro Ryu, ${ }^{1}$ Takumi Ehara, ${ }^{1}$ Kiyoshi Miyata, ${ }^{1}$ and Ken Onda*1 \\ ${ }^{1}$ Department of Chemistry, Kyushu University, 744 Motooka, Nishi, Fukuoka 829-0395 \\ E-mail: konda@chem.kyushu-univ.jp
}

\begin{abstract}
We have investigated the correlation between the photophysical properties and the excited-state detailed characteristics in a multiple-resonance-type thermally activated delayed fluorescence (TADF) molecule, DABNA-1, using time-resolved infrared vibrational spectroscopy. In comparison of the distinctive vibrational spectra in the fingerprint region, 1000 $1700 \mathrm{~cm}^{-1}$, to the simulated spectra by density functional theory calculations, we found the best calculation condition. On the basis of the calculations, we determined the excited-state geometries and molecular orbitals of the lowest excited singlet $\left(\mathrm{S}_{1}\right)$ and triplet $\left(\mathrm{T}_{1}\right)$ states as well as the ground state $\left(\mathrm{S}_{0}\right)$. We revealed that the similarity of the potential surfaces between $T_{1}$ and $S_{0}$ suppresses the nonradiative decay and causes the high fluorescence quantum yield via TADF process.
\end{abstract}

\section{Introduction}

Thermally activated delayed fluorescence (TADF) molecules received tremendous attention due to their unique ability to improve the efficiency of organic light-emitting diodes (OLEDs) ${ }^{1-5}$. TADF molecules can convert excitons in the lowest triplet state $\left(\mathrm{T}_{1}\right)$ to the lowest singlet excited state $\left(\mathrm{S}_{1}\right)$ via reverse intersystem crossing (RISC) driven by thermal excitation. To understand their detailed mechanism, a lot of experimental ${ }^{6-9}$ and theoretical ${ }^{10-12}$ studies have been performed. However, there are few spectroscopic data to be compared to the theoretical calculations besides the energy gap between $\mathrm{S}_{1}$ and $\mathrm{T}_{1}$ states $\left(\Delta E_{\mathrm{ST}}\right)^{13,14}$. Vibrational spectra in the wavenumber region less than $1700 \mathrm{~cm}^{-1}$, called fingerprint region, varies distinctively to reflect molecular characters. Thus, they are one of the ideal spectroscopic data to compare theoretical calculations ${ }^{15-17}$. Because there are not many methods to characterize a molecule in excited states, time-resolved infrared vibrational spectroscopy (TR-IR) is a variable method to explore photo-excited processes such as TADF with a high temporal resolution $(<1 \mathrm{ps})$.

To achieve an efficient RISC process in the room temperature, $\Delta E_{\mathrm{ST}}$ should be sufficiently small $(<0.2$ $\mathrm{eV}$ ). The basic design strategy for obtaining small $\Delta E_{\mathrm{ST}}$ is to separate the highest occupied molecular orbital (HOMO) from the lowest unoccupied molecular orbital (LUMO). Many TADF molecules achieve this HOMO and LUMO separation by connecting electron donor (D) and electron acceptor (A). However, D-A type TADF molecules exhibit broadband emission because they have a CT character in the excited states and a large structural fluctuation. This would become a problem to realize commercial products although they have high external quantum efficiency.

Recently, Hatakeyama's group proposed a novel approach to separate HOMO and LUMO utilizing multiple resonance (MR) effect ${ }^{18-22} .5,9-$ diphenyl-5,9diaza-13b-boranaphtho[3,2,1-de] anthracene (DABNA1 , the inset in Figure 1) is the first such TADF moleucle ${ }^{19}$. This molecule contains a triphenyl-boron framework, and the neighboring phenyl group is connected through two nitrogen atoms. The multiple resonance effects of boron and nitrogen atoms make HOMO and LUMO significantly separate and $\Delta E_{\mathrm{ST}}$ small $\sim 0.2 \mathrm{eV}^{19}$. Unlike typical D-A type TADF molecules, MR-type TADF molecules exhibit high $\mathrm{EQE}$ and narrowband emission due to more rigid molecular structure.

Many MR-type TADF molecules with high emission quantum yield and high color purity have been actively investigated and developed ${ }^{23-31}$. The sharp emission and large oscillator strength of these derivatives are expected from rigidity of structure due to multiple resonance effects. However, the experimental evidence of this is only the small Stokes shift $(<25 \mathrm{~nm})^{19}$. TADF activity is also expected to be modulated by molecular geometry dynamics ${ }^{32,33}$. Thus, more experimental and theoretical studies in the excited states are highly demanded.

Here, we have investigated the excited-state geometries and molecular orbitals in DABNA-1 using TR-IR in conjugation with density functional theory (DFT) calculations and time-dependent (TD-) DFT calculations. Using the same method, we reported the correlations between structural dynamics and TADF activities $^{34,35}$. Because the results of TD-DFT calculations strongly depend on a choice of functionals ${ }^{36}$, comparison to experimental data is essential. Thus, we evaluated the reliability of used functionals by comparing the calculated vibrational 
spectra by (TD-)DFT to the observed vibrational spectra in the fingerprint region. And then we obtained the geometries and molecular orbitals by the calculations using the conditions including the functional which best reproduced the observed spectra. On the basis of these results, we discuss the correlation between the photophysical properties and the excitedstate geometries and molecular orbitals.

\section{Experimental}

\section{Sample Preparation}

DABNA-1 was purchased from Lumitec, Inc. and used after purification. We prepared solutions of the purified molecules in dichloromethane (DCM) purchased from Kanto Kagaku.

\section{Fourier transform infrared (FT-IR) spectroscopy}

The infrared vibrational spectra in the ground state were recorded with an FT-IR spectrophotometer (Shimadzu, IRPrestige-21). The samples were measured in the $\mathrm{KBr}$ pellets, which were prepared by mixing the sample with $\mathrm{KBr}$ powder at a ratio of 1:100 and using a hydraulic press. $\mathrm{KBr}$ purchased from Kanto Kagaku.

\section{Raman spectroscopy}

The Raman spectra in the ground state were recorded with a microlaser Raman spectroscope (Horiba, LabRAM ARAMIS). The samples were measured in powder.

\section{TR-IR spectroscopy}

The experimental setup for the pump-probe type TR-IR measurements has been reported previously ${ }^{37-39}$. Briefly, a broadband mid-IR pulse for a probe light (pulse duration: $120 \mathrm{fs}$, bandwidth: $150 \mathrm{~cm}^{-1}$, tunable range: $1000-4000 \mathrm{~cm}^{-1}$ ) was generated by difference frequency generation (DFG) between signal and idler from an optical parametric amplifier (OPA) pumped by output of a Ti:sapphire regenerative amplifier. The pump pulse was obtained by an optical parametric oscillator (central wavelength: $440 \mathrm{~nm}$, pulse duration: $3 \mathrm{~ns}$ ) pumped by output of a nanosecond Nd:YAG laser (EKSPLA NL220). The time delay between the pump pulse and probe pulses was generated using a digital delay/pulse generator (Stanford Research Systems, DG645). The polarization angles of the pulse for the pump and probe pulses were set to the magic angle. The pump pulse fluence was approximately $1.27 \mathrm{~mJ} / \mathrm{cm}^{2}$. The sample solutions were continuously circulated through an IR cell equipped with $\mathrm{BaF}_{2}$ windows with an optical path length of $0.1 \mathrm{~mm}$. A probe pulse passed through the IR cell was dispersed by a $19 \mathrm{~cm}$ polychromator, followed by detected using a 64- channel mercury cadmium telluride (MCT) infrared detector array. The concentrations of the solutions were $5 \mathrm{mM}$. All measurements were conducted after 1-hour bubbling using $\mathrm{N}_{2}$ gas.

\section{Quantum chemical calculations.}

Quantum chemical calculations based on the density functional theory (DFT) and time-dependent (TD-)DFT were performed using the Gaussian 16, Rev. $A 01$ package. ${ }^{40}$ IR and Raman spectra were calculated after geometrical optimization of each electronic state. We adopted the three basis sets: 6-31g(d), 6-31g(d,p), and $6-311 \mathrm{~g}(\mathrm{~d})$ and the five hybrid functionals with different Hartree-Fock (HF) exchange percentage: O3LYP (12\%), B3LYP (20\%), PBE0 (25\%), BMK (42\%) and M062X (54\%) functionals by reference to previous studies ${ }^{19,23,24}$. The solvent effect was examined using the polarizable continuum model (PCM) of a dichloromethane solution (dielectric constant: 8.93, DCM). The vibrational frequencies of the calculated spectra were appropriately scaled to take into account frequency shifts caused by anharmonicity. The scaling factors of $0.980,0.975,0.965,0.970$, and 0.965 were adopted for O3LYP, B3LYP, PBE0, BMK, and M062X functionals, respectively.

\section{Results and discussion}

The optimized geometry in the ground state was examined by DFT calculations in comparison to FT-IR and Raman spectra. Figure 1a (PBE0) and S1 (all functionals) show the FT-IR spectrum and calculated IR spectra of DABNA-1 for the five hybrid functionals described in the experimental section. The calculated IR spectra generally well reproduce the FT-IR spectrum, but the spectral patterns at $1550-1650 \mathrm{~cm}^{-1}$ for BMK and M062X do not match that of FT-IR spectrum. Figure 1b (PBE0) and S2 (all functionals) show the Raman spectrum and the calculated Raman spectra. The calculated Raman spectra are also well consistent with the observed Raman spectrum, but the patterns at 1000 - $1250 \mathrm{~cm}^{-1}$ for BMK and at $1500-1650 \mathrm{~cm}^{-1}$ for M062X are slightly different from those corresponding to the observed one. These results suggest that the O3LYP, B3LYP and PBE0 are more suitable for examining the optimized geometry in the ground state.

To assign the TR-IR spectra to the electronic excited states, we measured the temporal evolutions of the TR-IR spectra. Figure 2 a shows TR-IR spectra up to $50 \mathrm{~ns}$ in a dichloromethane (DCM) solution at 1120 - $1240 \mathrm{~cm}^{-1}$ after photoexcitation. Both the transient absorption bands (upward) and bleach bands (downward) emerge immediately after photoexcitation 
(a)

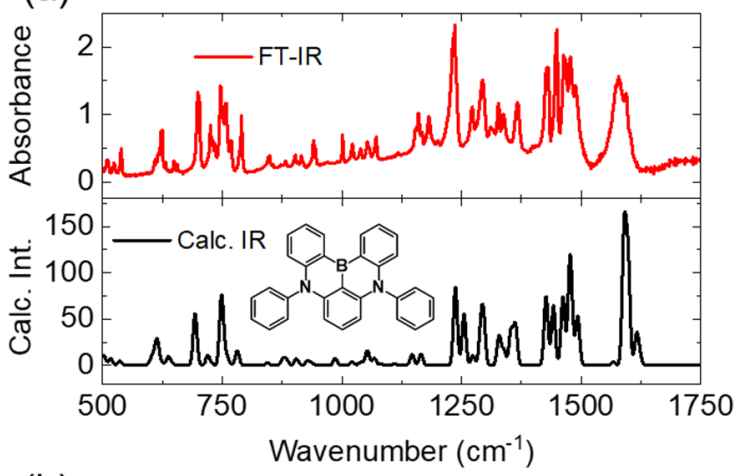

(b)

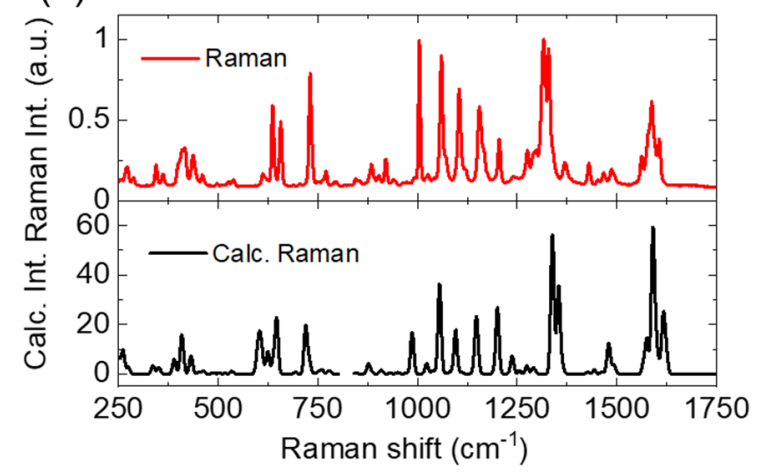

Figure 1. Comparison of the observed spectra (upper) and calculated vibrational spectra (lower) for (a) FT-IR and (b) Raman spectroscopy of DABNA-1. Calculated spectra were obtained using PBE0/6-31g $(\mathrm{d}, \mathrm{p})$. Solvent effect was taken into account using PCM for DCM. (Inset of a) Molecular structure of DABNA-1.

less than 1 ps. Black circles in Figure $2 b$ represent the temporal profile of the transient absorption band at $1232 \mathrm{~cm}^{-1}$. By fitting using an exponential function (red line in Figure 2b), we obtained a fast decay component $\sim 7 \mathrm{~ns}$ and a component that would not change up to 50 ns (shown by dashed line in Figure 2b).
Considering that the decrease of the bleach bands corresponds to the recovery of the ground state population, the fast component is attributed to the deactivation process of $S_{1}$ to $S_{0}$ after photoexcitation, and this process is dominant compared to the intersystem crossing from $S_{1}$ to $T_{1}$. This result is consistent with the previous study; the main component of DABNA-1 emission is prompt fluorescence rather than delayed fluorescence ${ }^{19}$. Furthermore, the time constant $\sim 7 \mathrm{~ns}$ is in good agreement with the prompt fluorescence lifetime $\sim 9.5$ ns previously reported ${ }^{19}$.

The relatively minor component with a much longer time constant than $50 \mathrm{~ns}$ indicates that some population remains in an excited state even at $50 \mathrm{~ns}$ after the fast decay. Given that DABNA-1 has TADF activity, the remaining component after fluorescence lifetime is attributed to the transient vibrational absorption in the $T_{1}$ state. From these results, the TRIR spectra at $1 \mathrm{~ns}$ and $50 \mathrm{~ns}$ are assigned to the vibrational spectra of the $S_{1}$ and $T_{1}$ states, respectively. The fact that the spectra are not drastically changed up to $50 \mathrm{~ns}$ as shown in Figure 2a and S3 indicates that the molecular geometry and electron distribution are not much changed along with intersystem crossing (ISC) from $S_{1}$ to $T_{1}$.

Figure 3 compares the TR-IR spectrum assigned to $\mathrm{S}_{1}$ at $1 \mathrm{~ns}$ to the calculated difference IR spectra between the $S_{1}$ and $S_{0}$ states by TD-DFT calculations using the five functionals. The calculated spectra using BMK and M062X does not reproduce the band positions and shapes in the TR-IR spectrum in the whole wavenumber regions. The calculated spectrum using O3LYP is rather similar to the TR-IR spectrum
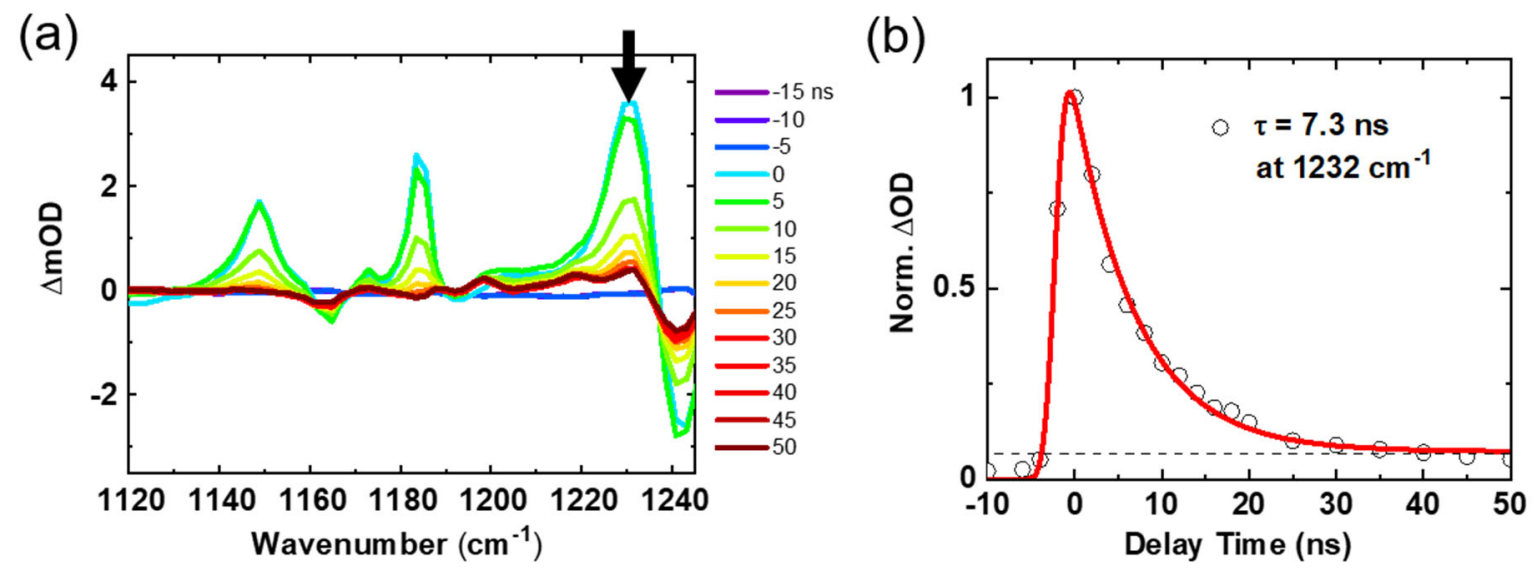

Figure 2. (a) Temporal evolutions of TR-IR spectra in DCM solution ranging from 1120 to $1240 \mathrm{~cm}^{-1}$ after photoexcitation with $440 \mathrm{~nm}$. (b) Temporal profile at $1232 \mathrm{~cm}^{-1}$ (black circles) and fitting curve using an exponential function (red line) 
but the spectral pattern at $1150-1250 \mathrm{~cm}^{-1}$ do not match each other. Compared to these calculated spectra, the spectra using B3LYP and PBE0 are in good agreement with the TR-IR spectrum in all wavenumber range.

Figure S4 compares the TR-IR spectrum at $50 \mathrm{~ns}$ to the calculated difference IR spectra between $T_{1}$ and $\mathrm{S}_{0}$ states by DFT calculation using the five functionals. The calculated spectra using BMK and M062X in the $\mathrm{T}_{1}$ state did not reproduce the spectral shape for the experimental spectrum in the region around 1200-1400 $\mathrm{cm}^{-1}$, whereas the calculated spectra using PBE0 and B3LYP functional are in good agreement with the TRIR spectrum. This trend is similar to that of the $S_{1}$ state although their calculation methods are different: TDDFT for $\mathrm{S}_{1}$ and DFT for $\mathrm{T}_{1}$. Figure 4 compares the TRIR spectra to the best agreed calculated spectra for the $\mathrm{S}_{1}$ and $\mathrm{T}_{1}$ states.

The B3LYP and PBE0 functionals are hybrid functional with $\mathrm{HF}$ exchange of $20-25 \%$. These functionals have also been used in the previous reserches ${ }^{19,23,24}$. These experimental results support that HF exchange percent of $20-25 \%$ is suitable for examining the geometries in the excited states for MR type molecules. Besides, we confirmed the calculated spectra did not depend on the choice of basis set (Figure

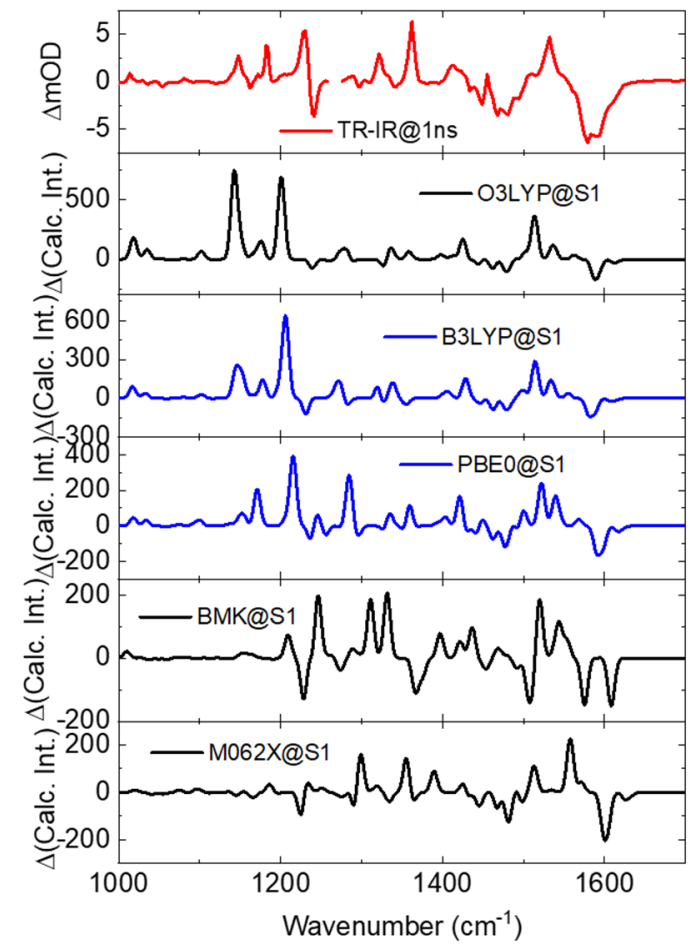

Figure 3. Dependence on the functional for calculated spectrum in the $S_{1}$ state. The basis set was $6-31 \mathrm{~g}(\mathrm{~d}, \mathrm{p})$ and solvent effect was taken into account using PCM for DCM.

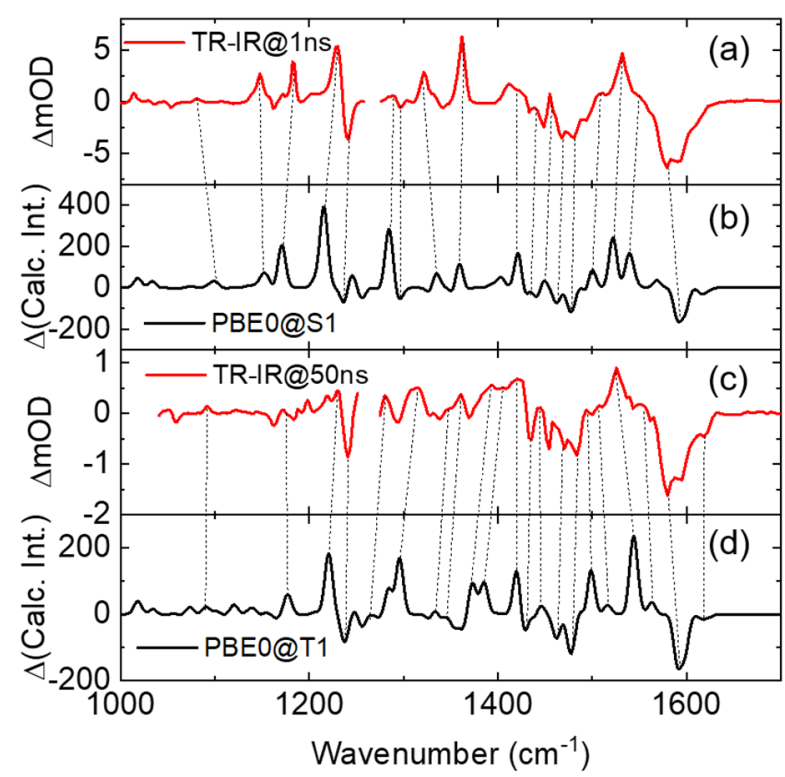

Figure 4. Comparison of $(\mathrm{a}, \mathrm{c})$ observed spectra and $(\mathrm{b}, \mathrm{d})$ calculated vibrational spectra for $(a, b) S_{1}$ and $(c, d) T_{1}$ states of DABNA-1. The range neighboring $1265 \mathrm{~cm}^{-1}$ could not be measured due to DCM solvent absorption. Calculated spectra were obtained using TD-DFT for $\mathrm{S}_{1}$ state and DFT for $\mathrm{T}_{1}$ with PBE0/6-31g(d,p). Solvent effect was taken into account using PCM for DCM.

S5). Incorporation of the dielectric effect from a solvent using PCM showed trivial effects (Figure S6).

We considered the detailed molecular structures in each electronic state on the basis of the calculations in the best agreement with the observed spectra. Figure 5 shows the optimized geometries in each state, and Table 1 shows structural parameters: bond lengths, (a) $\mathrm{S}_{0}$ state

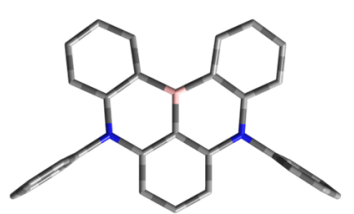

(c) $\mathrm{T}_{1}$ state

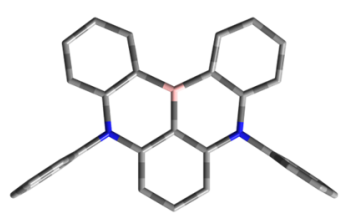

(b) $\mathrm{S}_{1}$ state

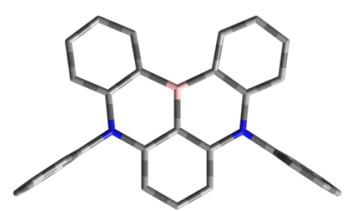

(d) label

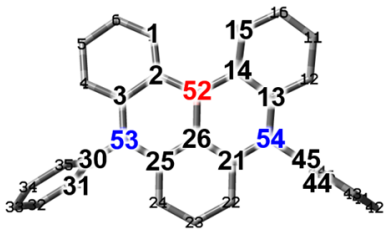

Figure 5. (a, b, c) Optimized structures for each state. Calculations were performed using TD-DFT for $\mathrm{S}_{1}$ state and DFT for $\mathrm{S}_{0}$ and $\mathrm{T}_{1}$ state with PBE0/6-31g(d,p). Solvent effect was taken into account using PCM for DCM. (d) Atom labels. hydrogen atoms are omitted for clarity. 
Table 1. Structural parameters with optimized geometries for $S_{0}, S_{1}$, and $T_{1}$ states. Calculations were performed using TD-DFT for $\mathrm{S}_{1}$ state and DFT for $\mathrm{S}_{0}$ and $\mathrm{T}_{1}$ states with PBE0/6-31g(d,p). Solvent effect was taken into account using PCM for DCM. Atom labels are shown in Figure 5d

\begin{tabular}{|c|c|c|c|c|c|c|}
\hline \multirow{2}{*}{ PBE0/6-31g(d,p) } & $\mathrm{S}_{0}$ & $\mathrm{~S}_{1}$ & $\mathrm{~T}_{1}$ & $\Delta\left(\mathrm{S}_{1}-\mathrm{S}_{0}\right)$ & $\Delta\left(T_{1}-S_{0}\right)$ & $\Delta\left(\mathrm{T}_{1}-\mathrm{S}_{0}\right) / \Delta\left(\mathrm{S}_{1}-\mathrm{S}_{0}\right)$ \\
\hline & \multicolumn{6}{|c|}{ bond length } \\
\hline B52-C2 (B52-C14) & 1.5447 & 1.5376 & 1.5415 & 0.0072 & 0.0032 & 0.4463 \\
\hline B52-C26 & 1.5138 & 1.5283 & 1.5158 & -0.0145 & -0.0020 & 0.1387 \\
\hline N53-C3 (N54-C13) & 1.3965 & 1.4093 & 1.4092 & -0.0127 & -0.0127 & 0.9992 \\
\hline N53-C25 (N54-C21) & 1.3929 & 1.3867 & 1.3897 & 0.0062 & 0.0033 & 0.5217 \\
\hline $\mathrm{C} 2-\mathrm{C} 3(\mathrm{C} 13-\mathrm{C} 14)$ & 1.4205 & 1.4338 & 1.4329 & -0.0133 & -0.0125 & 0.9355 \\
\hline C25-C26 (C21-C26) & 1.4195 & 1.4059 & 1.4125 & 0.0136 & 0.0070 & 0.5181 \\
\hline N54-C45 (N53-C30) & 1.4347 & 1.4368 & 1.4371 & -0.0021 & -0.0024 & 1.1635 \\
\hline \multirow[t]{2}{*}{ C1-C15 } & 3.3275 & 3.3622 & 3.3695 & -0.0347 & -0.0420 & 1.2114 \\
\hline & \multicolumn{6}{|c|}{ angle } \\
\hline $\mathrm{C} 2-\mathrm{B} 52-\mathrm{C} 14$ & 129.369 & 129.959 & 129.937 & -0.590 & -0.569 & 0.964 \\
\hline $\begin{array}{c}\text { C2-B52-C26 } \\
(\mathrm{C} 14-B 52-C 26)\end{array}$ & 115.316 & 115.021 & 115.031 & 0.295 & 0.284 & 0.964 \\
\hline $\begin{array}{c}\text { C3-N53-C25 } \\
\text { (C13-N54-C21) }\end{array}$ & 123.971 & 124.525 & 124.387 & -0.555 & -0.416 & 0.751 \\
\hline \multirow[t]{2}{*}{$\begin{array}{c}\text { C3-N53-C30 } \\
\text { (C13-N54-C45) }\end{array}$} & 118.303 & 117.575 & 117.724 & 0.728 & 0.579 & 0.795 \\
\hline & \multicolumn{6}{|c|}{ dihedral angle } \\
\hline C1-C2-C14-C15 & 21.750 & 16.568 & 16.274 & 5.182 & 5.476 & 1.057 \\
\hline C3-N53-N54-C13 & 14.232 & 10.423 & 10.337 & 3.810 & 3.896 & 1.023 \\
\hline $\begin{array}{l}\text { C3-N53-C30-C31 } \\
\text { (C13-N54-C45-C44) }\end{array}$ & 87.642 & 87.704 & 88.053 & -0.062 & -0.411 & 6.635 \\
\hline
\end{tabular}

angles, and dihedral angles in each state. It was clarified that the diaza-boranaphtho-anthracene unit, which is the central scaffold of DABNA-1, mainly maintained its flatness in all states. As confirmed experimentally from the TR-IR spectra, the structural changes along with ISC are very small. These results are consistent with the previous report ${ }^{19,23}$. We confirmed the excited state geometries and its rigidity with the experimental evidence.

These structural features are entirely different from typical D-A type TADF molecules we already reported $^{34,35}$ in which the structural change is small in

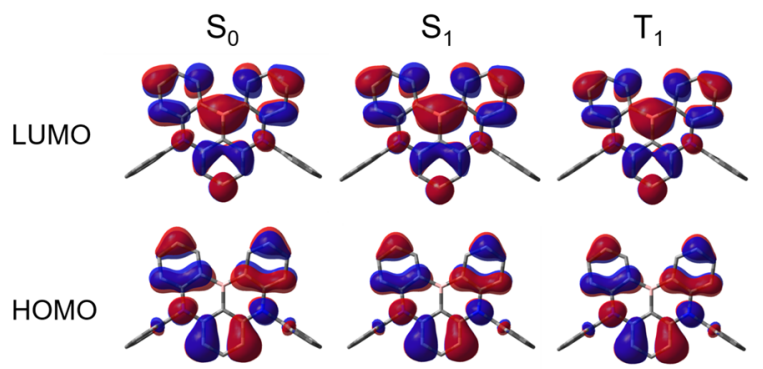

Figure 6. HOMO and LUMO in $\mathrm{S}_{0}, \mathrm{~S}_{1}$, and $\mathrm{T}_{1}$ states. Calculations were performed using TD-DFT for $\mathrm{S}_{1}$ state and DFT for $\mathrm{S}_{0}$ and $\mathrm{T}_{1}$ state. The functional and basis set was PBE0 and $6-31 \mathrm{~g}(\mathrm{~d}, \mathrm{p})$, respectively. Solvent effect was taken into account using PCM for DCM. the excited state. This rigidity must bring about the high oscillator strength and a narrow FWHM with a small Stokes shift of DABNA-1. Table S1-S4 show the structural parameters obtained from the other functionals. While the results of B3LYP and PBE0 functionals show similar geometries, the results of the other functionals show a slight difference in the helical twisting of the main skeleton in the excited state.

Although the main skeleton of DABNA-1 does not change drastically in the excited states, there is a slight difference in geometry between the ground and excited states. Focusing on the bond lengths neighboring the boron and nitrogen atoms, they are changed slightly in the excited states. As shown in Figure 6, the area where HOMO was distributed became longer in the excited states, and the area where LUMO was distributed became shorter in the excited states. These changes were caused by the change in the orbital distribution due to electronic excitation. Furthermore, focusing on the diaza-boranaphtho-anthracene unit, the helical twisting in the excited states was slightly relaxed than in the ground state. The distance between carbon atoms on the edges of the two phenazaborines (C1-C15 in Figure 5) increases, and the dihedral angle between the two phenazaborines decreases. This means that the skeleton becomes flatter in the excited states. The tendency of these slight structural changes is observed for the other functionals that reproduced the experimental spectra. 
There is a very little but significant difference in geometry between the $S_{1}$ and $T_{1}$ states. We compare the amount of change in each structural parameter from the $\mathrm{S}_{0}$ state to the $\mathrm{S}_{1}$ and $\mathrm{T}_{1}$ states. The normalized values of the variation from $S_{0}$ to $S_{1}$ and $T_{1}\left(\Delta\left(T_{1}-S_{0}\right) / \Delta\left(S_{1}\right.\right.$ $\left.\mathrm{S}_{0}\right)$ ) were calculated and are shown in Table 1. If this value is less than unity for the most structural parameters, meaning that the geometry in the $T_{1}$ state was closer to that in the $\mathrm{S}_{0}$ state than that in the $\mathrm{S}_{1}$ state. This indicates that the potential surfaces of the $S_{0}$ and $\mathrm{T}_{1}$ states are almost the same each other. In this case, the Franck-Condon factor for the nonradiative decay between the $S_{0}$ and $T_{1}$ states becomes very small, and the nonradiative process is highly suppressed (the energy gap law). A previous study reported that the lifetime of TADF for DABNA-1 was $\sim 94 \mu \mathrm{s}^{19}$, which is consistent with this speculation.
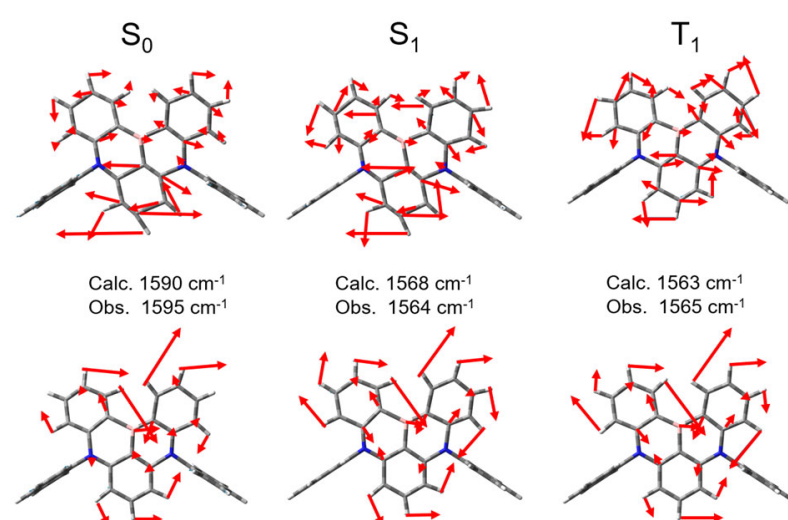

Calc. $1255 \mathrm{~cm}^{-1}$ Obs. $1240 \mathrm{~cm}^{-1}$
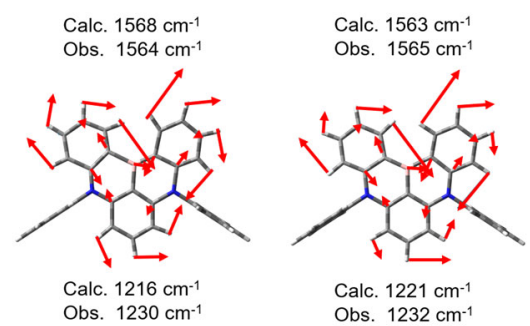

Figure 7. Comparison of vibrational modes of $S_{0}, S_{1}$, and $T_{1}$ states. Calculations were performed using TD-DFT for $\mathrm{S}_{1}$ state and DFT for $\mathrm{S}_{0}$ and $\mathrm{T}_{1}$ state with PBE0/6-31g(d,p) level. Solvent effect was taken into account using PCM for DCM.

The bands are shifted in the TR-IR spectrum even though the geometries in the excited states are not changed drastically from the ground state. Because the structural change in the ground state and the excited states is suppressed, the normal vibrational mode should be the same in each state. We assigned the vibrational modes to some major peaks on the basis of the DFT calculations (Figure S7-9). It was revealed that most of the vibrational modes in the excited states were red-shifted than those in the ground state (Figure 7). This result indicates that the potential in the excited state is slightly shallower than that in the ground state, which causes the IR spectral change in the excited states.

\section{Summary}

We investigated the molecular geometries and molecular orbitals in the lowest singlet $\left(\mathrm{S}_{1}\right)$ and triplet
$\left(\mathrm{T}_{1}\right)$ excited states as well as the ground state $\left(\mathrm{S}_{0}\right)$ in the TADF molecule using multiple resonance effects, DABNA-1, using FT-IR, Raman, and TR-IR spectroscopies. By comparing these spectra to the calculated spectra by DFT or TD-DFT calculations, we determined the best calculation condition. We found a little spectral change from the $S_{1}$ to $T_{1}$ states, indicating that the structural change along with intersystem crossing is very small. We carefully examine the difference in geometry between the states on the basis of the calculations, and found that similarity in vibrational potential between the $\mathrm{S}_{0}$ and $\mathrm{T}_{1}$ states causes the long lifetime and efficient TADF process of the $T^{1}$ state.

\section{Acknowledgment}

This work was supported in part by JSPS KAKENHI Grant Number JP17H06375, JP18H05170, and JP20H05106. The computations were performed using the Research Center for Computational Science (National Institute of Natural Sciences) and Research Institute for Information Technology (Kyushu University).

\section{References}

1 H. Uoyama, K. Goushi, K. Shizu, H. Nomura, C. Adachi, Nature 2012, 492, 234.

2 F. B. Dias, K. N. Bourdakos, V. Jankus, K. C. Moss, K. T. Kamtekar, V. Bhalla, J. Santos, M. R. Bryce, A. P. Monkman, Advanced Materials 2013, 25, 3707.

3 J. W. Sun, J. H. Lee, C. K. Moon, K. H. Kim, H. Shin, J. J. Kim, Advanced Materials 2014, 26 , 5684.

$4 \quad$ S. Hirata, Y. Sakai, K. Masui, H. Tanaka, S. Y. Lee, H. Nomura, N. Nakamura, M. Yasumatsu, H. Nakanotani, Q. Zhang, K. Shizu, H. Miyazaki, C. Adachi, Nature Materials 2015, 14, 330.

$5 \quad$ H. Kaji, H. Suzuki, T. Fukushima, K. Shizu, K. Suzuki, S. Kubo, T. Komino, H. Oiwa, F. Suzuki, A. Wakamiya, Y. Murata, C. Adachi, Nature Communications 2015, 6, 1.

6 T. Hosokai, H. Matsuzaki, H. Nakanotani, K. Tokumaru, T. Tsutsui, A. Furube, K. Nasu, H. Nomura, M. Yahiro, C. Adachi, Science Advances 2017, 3, e1603282.

7 H. Noda, X. K. Chen, H. Nakanotani, T. Hosokai, M. Miyajima, N. Notsuka, Y. Kashima, J. L. Brédas, C. Adachi, Nature Materials 2019, $18,1084$.

8 T. Kobayashi, A. Niwa, K. Takaki, S. Haseyama, T. Nagase, K. Goushi, C. Adachi, H. Naito, Physical Review Applied 2017, 7, 1. 
9 E. W. Evans, Y. Olivier, Y. Puttisong, W. K. Myers, T. J. H. Hele, S. M. Menke, T. H. Thomas, D. Credgington, D. Beljonne, R. H. Friend, N. C. Greenham, Journal of Physical Chemistry Letters 2018, 9, 4053.

X. K. Chen, D. Kim, J. L. Brédas, Accounts of Chemical Research 2018, 51, 2215.

M. K. Etherington, J. Gibson, H. F. Higginbotham, T. J. Penfold, A. P. Monkman, Nature Communications 2016, 7, 13680.

J. Gibson, A. P. Monkman, T. J. Penfold, ChemPhysChem 2016, 17, 2956.

S. Huang, Q. Zhang, Y. Shiota, T. Nakagawa, K. Kuwabara, K. Yoshizawa, C. Adachi, Journal of Chemical Theory and Computation 2013, 9, 3872.

X. K. Chen, S. F. Zhang, J. X. Fan, A. M. Ren, Journal of Physical Chemistry C 2015, 119, 9728.

15 J. Clarkson, W. E. Smith, Journal of Molecular Structure 2003, 655, 413.

16 N. Sundaraganesan, S. Ilakiamani, P. Subramani, B. D. Joshua, Spectrochimica Acta - Part A: Molecular and Biomolecular Spectroscopy 2007, 67, 628.

B. Klaumünzer, D. Kröner, P. Saalfrank, Journal of Physical Chemistry B 2010, 114, 10826.

18 H. Hirai, K. Nakajima, S. Nakatsuka, K. Shiren, J. Ni, S. Nomura, T. Ikuta, T. Hatakeyama, Angewandte Chemie - International Edition 2015, 54, 13581.

19 T. Hatakeyama, K. Shiren, K. Nakajima, S. Nomura, S. Nakatsuka, K. Kinoshita, J. Ni, Y. Ono, T. Ikuta, Advanced Materials 2016, 28 , 2777.

20 Y. Kondo, K. Yoshiura, S. Kitera, H. Nishi, S. Oda, H. Gotoh, Y. Sasada, M. Yanai, T. Hatakeyama, Nature Photonics 2019, 13, 678. N. Ikeda, S. Oda, R. Matsumoto, M. Yoshioka, D. Fukushima, K. Yoshiura, N. Yasuda, T. Hatakeyama, Advanced Materials 2020, 32, 1. S. Oda, T. Hatakeyama, W. Kumano, T. Hama, R. Kawasumi, K. Yoshiura, Angewandte Chemie 2020, 1.

L. Lin, J. Fan, L. Cai, C. K. Wang, Molecular Physics 2018, 116, 19.
T. Northey, T. J. Penfold, Organic Electronics 2018, 59, 45. Zheng, H. Meng, J. L. Zuo, W. Huang, Angewandte Chemie - International Edition 2018, 57, 11316.

Y. Zhang, D. Zhang, J. Wei, Z. Liu, Y. Lu, L. Duan, Angewandte Chemie 2019, 131, 17068. A. Pershin, D. Hall, V. Lemaur, J. C. SanchoGarcia, L. Muccioli, E. Zysman-Colman, D.
X. Liang, Z. P. Yan, H. B. Han, Z. G. Wu, Y. X.
Beljonne, Y. Olivier, Nature Communications 2019, 10, 3.

28 S. M. Suresh, E. Duda, D. Hall, Z. Yao, S. Bagnich, A. M. Z. Slawin, H. Bässler, D. Beljonne, M. Buck, Y. Olivier, A. Köhler, E. Zysman-Colman, Journal of the American Chemical Society 2020, 142, 6588.

29 M. Yang, I. S. Park, T. Yasuda, Journal of the American Chemical Society 2020, 142, 19468.

30 D. Hall, S. M. Suresh, P. L. dos Santos, E. Duda, S. Bagnich, A. Pershin, P. Rajamalli, D. B. Cordes, A. M. Z. Slawin, D. Beljonne, A. Köhler, I. D. W. Samuel, Y. Olivier, E. ZysmanColman, Advanced Optical Materials 2020, 8.

31 Y. Zhang, D. Zhang, J. Wei, X. Hong, Y. Lu, D. $\mathrm{Hu}, \mathrm{G}$. Li, Z. Liu, Y. Chen, L. Duan, Angewandte Chemie 2020, 132, 17652.

32 R. S. Nobuyasu, Z. Ren, G. C. Griffiths, A. S. Batsanov, P. Data, S. Yan, A. P. Monkman, M. R. Bryce, F. B. Dias, Advanced Optical Materials 2016, 4, 597.

33 T. J. Penfold, E. Gindensperger, C. Daniel, C. M. Marian, Chemical Reviews 2018, 118, 6975.

34 M. Saigo, K. Miyata, S. Tanaka, H. Nakanotani, C. Adachi, K. Onda, Journal of Physical Chemistry Letters 2019, 10, 2475.

35 Y. Shimoda, K. Miyata, M. Saigo, Y. Tsuchiya, C. Adachi, K. Onda, Journal of Chemical Physics 2020, 153, 204702.

36 D. Jacquemin, V. Wathelet, E. A. Perpète, C. Adamo, Journal of Chemical Theory and Computation 2009, 5, 2420.

37 N. Fukazawa, T. Tanaka, T. Ishikawa, Y. Okimoto, S. Koshihara, T. Yamamoto, M. Tamura, R. Kato, K. Onda, The Journal of Physical Chemistry C 2013, 117, 13187.

38 T. Mukuta, N. Fukazawa, K. Murata, A. Inagaki, M. Akita, S. Tanaka, S. Koshihara, K. Onda, Inorganic Chemistry 2014, 53, 2481.

39 T. Mukuta, S. Tanaka, A. Inagaki, S. Y. Koshihara, K. Onda, ChemistrySelect 2016, 1, 2802.

40 M. J. Frisch, G. W. Trucks, H. B. Schlegel, G. E. Scuseria, M. A. Robb, J. R. Cheeseman, G. Scalmani, V. Barone, G. A. Petersson, H. Nakatsuji, X. Li, M. Caricato, A. V. Marenich, J. Bloino, B. G. Janesko, R. Gomperts, B. Mennucci, H. P. Hratchian, J. V. Ortiz, A. F. Izmaylov, J. L. Sonnenberg, D. Williams-Young, F. Ding, F. Lipparini, F. Egidi, J. Goings, B. Peng, A. Petrone, T. Henderson, D. Ranasinghe, V. G. Zakrzewski, J. Gao, N. Rega, G. Zheng, W. Liang, M. Hada, M. Ehara, K. Toyota, R. Fukuda, J. Hasegawa, M. Ishida, T. Nakajima, Y. Honda, O. Kitao, H. Nakai, T. Vreven, K. Throssell, J. Montgomery, J. A., J. E. Peralta, F. 
Ogliaro, M. J. Bearpark, J. J. Heyd, E. N.

Brothers, K. N. Kudin, V. N. Staroverov, T. A.

Keith, R. Kobayashi, J. Normand, K.

Raghavachari, A. P. Rendell, J. C. Burant, S. S.

Iyengar, J. Tomasi, M. Cossi, J. M. Millam, M.

Klene, C. Adamo, R. Cammi, J. W. Ochterski, R.

L. Martin, K. Morokuma, O. Farkas, J. B.

Foresman, D. J. Fox, Gaussian 16, Revision

A.03, Gaussian, Inc., Wallingford CT, 2016. 


\title{
Supporting Information
}

Characterization of Excited States in a Multiple-Resonance-Type Thermally Activated Delayed Fluorescence Molecule Using Time-resolved Infrared Spectroscopy

\author{
Yuushi Shimoda, ${ }^{1}$ Masaki Saigo, ${ }^{1}$ Tomohiro Ryu, ${ }^{1}$ Takumi Ehara, ${ }^{1}$ Kiyoshi Miyata, ${ }^{1}$ and Ken Onda*1 \\ ${ }^{1}$ Department of Chemistry, Kyushu University, 744 Motooka, Nishi, Fukuoka 829-0395 \\ E-mail:konda@chem.kyushu-univ.jp
}

Table of Contents

Table S1-S4

Figures S1 - 10 


\section{Table S1-S4}

Table S1. The structural parameter with optimized structures for each state. Calculated using TD-DFT for $\mathrm{S}_{1}$ state and DFT for $\mathrm{S}_{0}$ and $\mathrm{T}_{1}$ state with O3LYP/6-31g(d,p). Solvent effect was taken into account using PCM for DCM.

\begin{tabular}{|c|c|c|c|c|c|c|}
\hline \multirow{2}{*}{ O3LYP/6-31g(d,p) } & $\mathrm{S}_{0}$ & $\mathrm{~S}_{1}$ & $\mathrm{~T}_{1}$ & $\Delta\left(\mathrm{S}_{1}-\mathrm{S}_{0}\right)$ & $\Delta\left(T_{1}-S_{0}\right)$ & $\Delta\left(\mathrm{T}_{1}-\mathrm{S}_{0}\right) / \Delta\left(\mathrm{S}_{1}-\mathrm{S}_{0}\right)$ \\
\hline & \multicolumn{6}{|c|}{ bond length } \\
\hline B52-C2 (B52-C14) & 1.5492 & 1.5401 & 1.5460 & 0.0090 & 0.0032 & 0.3518 \\
\hline B52-C26 & 1.5170 & 1.5392 & 1.5191 & -0.0222 & -0.0021 & 0.0959 \\
\hline N53-C3 (N54-C13) & 1.4027 & 1.4212 & 1.4123 & -0.0185 & -0.0096 & 0.5165 \\
\hline N53-C25 (N54-C21) & 1.4002 & 1.3897 & 1.4010 & 0.0105 & -0.0008 & -0.0771 \\
\hline C2-C3 (C13-C14) & 1.4263 & 1.4374 & 1.4391 & -0.0111 & -0.0128 & 1.1512 \\
\hline C25-C26 (C21-C26) & 1.4249 & 1.4093 & 1.4183 & 0.0156 & 0.0066 & 0.4211 \\
\hline N54-C45 (N53-C30) & 1.4419 & 1.4440 & 1.4442 & -0.0021 & -0.0022 & 1.0613 \\
\hline \multirow[t]{2}{*}{ C1-C15 } & 3.3576 & 3.3885 & 3.3914 & -0.0309 & -0.0338 & 1.0966 \\
\hline & \multicolumn{6}{|c|}{ angle } \\
\hline C2-B52-C14 & 129.479 & 130.278 & 129.931 & -0.800 & -0.453 & 0.5660 \\
\hline $\begin{array}{c}\text { C2-B52-C26 } \\
\text { (C14-B52-C26) }\end{array}$ & 115.261 & 114.861 & 115.034 & 0.400 & 0.226 & 0.5661 \\
\hline $\begin{array}{l}\text { C3-N53-C25 } \\
\text { (C13-N54-C21) }\end{array}$ & 123.762 & 124.209 & 124.201 & -0.447 & -0.439 & 0.9818 \\
\hline \multirow[t]{2}{*}{$\begin{array}{c}\text { C3-N53-C30 } \\
\text { (C13-N54-C45) }\end{array}$} & 118.413 & 117.639 & 117.939 & 0.775 & 0.475 & 0.6127 \\
\hline & \multicolumn{6}{|c|}{ dihedral angle } \\
\hline C1-C2-C14-C15 & 24.174 & 18.516 & 19.082 & 5.658 & 5.092 & 0.8999 \\
\hline C3-N53-N54-C13 & 16.170 & 12.260 & 12.365 & 3.911 & 3.805 & 0.9729 \\
\hline $\begin{array}{c}\text { C3-N53-C30-C31 } \\
\text { (C13-N54-C45-C44) }\end{array}$ & 87.926 & 87.911 & 87.993 & 0.015 & -0.067 & -4.3806 \\
\hline
\end{tabular}

Table S2. The structural parameter with optimized structures for each state. Calculated using TD-DFT for $\mathrm{S}_{1}$ state and DFT for $\mathrm{S}_{0}$ and $\mathrm{T}_{1}$ state with B3LYP/6-31g(d,p). Solvent effect was taken into account using PCM for DCM.

\begin{tabular}{|c|c|c|c|c|c|c|}
\hline \multirow{2}{*}{ B3LYP/6-31g(d,p) } & $\mathrm{S}_{0}$ & $\mathrm{~S}_{1}$ & $\mathrm{~T}_{1}$ & $\Delta\left(\mathrm{S}_{1}-\mathrm{S}_{0}\right)$ & $\Delta\left(\mathrm{T}_{1}-\mathrm{S}_{0}\right)$ & $\Delta\left(\mathrm{T}_{1}-\mathrm{S}_{0}\right) / \Delta\left(\mathrm{S}_{1}-\mathrm{S}_{0}\right)$ \\
\hline & \multicolumn{6}{|c|}{ bond length } \\
\hline B52-C2 (B52-C14) & 1.5476 & 1.5392 & 1.5438 & 0.0084 & 0.0038 & 0.449 \\
\hline B52-C26 & 1.5162 & 1.5343 & 1.5178 & -0.0181 & -0.0016 & 0.087 \\
\hline N53-C3 (N54-C13) & 1.4057 & 1.4212 & 1.4169 & -0.0155 & -0.0112 & 0.721 \\
\hline N53-C25 (N54-C21) & 1.4024 & 1.3941 & 1.4011 & 0.0083 & 0.0013 & 0.156 \\
\hline C2-C3 (C13-C14) & 1.4257 & 1.4386 & 1.4391 & -0.0129 & -0.0134 & 1.038 \\
\hline C25-C26 (C21-C26) & 1.4247 & 1.4101 & 1.4183 & 0.0146 & 0.0065 & 0.441 \\
\hline N54-C45 (N53-C30) & 1.4442 & 1.4465 & 1.4467 & -0.0023 & -0.0025 & 1.099 \\
\hline \multirow[t]{2}{*}{ C1-C15 } & 3.3297 & 3.3610 & 3.3649 & -0.0313 & -0.0352 & 1.125 \\
\hline & \multicolumn{6}{|c|}{ angle } \\
\hline $\mathrm{C} 2-\mathrm{B} 52-\mathrm{C} 14$ & 129.178 & 129.802 & 129.610 & -0.623 & -0.432 & 0.693 \\
\hline $\begin{array}{c}\text { C2-B52-C26 } \\
\text { (C14-B52-C26) }\end{array}$ & 115.410 & 115.099 & 115.195 & 0.311 & 0.215 & 0.693 \\
\hline $\begin{array}{c}\text { C3-N53-C25 } \\
\text { (C13-N54-C21) }\end{array}$ & 123.712 & 124.223 & 124.143 & -0.510 & -0.431 & 0.844 \\
\hline \multirow[t]{2}{*}{$\begin{array}{c}\text { C3-N53-C30 } \\
\text { (C13-N54-C45) }\end{array}$} & 118.422 & 117.673 & 117.894 & 0.749 & 0.528 & 0.706 \\
\hline & \multicolumn{6}{|c|}{ dihedral angle } \\
\hline $\mathrm{C} 1-\mathrm{C} 2-\mathrm{C} 14-\mathrm{C} 15$ & 22.341 & 17.185 & 17.181 & 5.156 & 5.160 & 1.001 \\
\hline C3-N53-N54-C13 & 14.870 & 11.266 & 11.114 & 3.604 & 3.756 & 1.042 \\
\hline $\begin{array}{c}\text { C3-N53-C30-C31 } \\
\text { (C13-N54-C45-C44) }\end{array}$ & 87.884 & 87.857 & 88.072 & 0.027 & -0.188 & -6.854 \\
\hline
\end{tabular}

Table S3. The structural parameter with optimized structures for each state. Calculated using TD-DFT for $\mathrm{S}_{1}$ state and DFT for $\mathrm{S}_{0}$ and $\mathrm{T}_{1}$ state with BMK/6-31g(d,p). Solvent effect was taken into account using PCM for DCM. 
11

\begin{tabular}{|c|c|c|c|c|c|c|}
\hline \multirow{2}{*}{ BMK/6-31g(d,p) } & $\mathrm{S}_{0}$ & $S_{1}$ & $\mathrm{~T}_{1}$ & $\Delta\left(\mathrm{S}_{1}-\mathrm{S}_{0}\right)$ & $\Delta\left(\mathrm{T}_{1}-\mathrm{S}_{0}\right)$ & $\Delta\left(\mathrm{T}_{1}-\mathrm{S}_{0}\right) / \Delta\left(\mathrm{S}_{1}-\mathrm{S}_{0}\right)$ \\
\hline & \multicolumn{6}{|c|}{ bond length } \\
\hline B52-C2 (B52-C14) & 1.5398 & 1.5343 & 1.5351 & 0.0055 & 0.0047 & 0.8517 \\
\hline B52-C26 & 1.5086 & 1.5148 & 1.5090 & -0.0061 & -0.0003 & 0.0506 \\
\hline N53-C3 (N54-C13) & 1.3996 & 1.4062 & 1.4138 & -0.0066 & -0.0142 & 2.1548 \\
\hline N53-C25 (N54-C21) & 1.3956 & 1.3942 & 1.3911 & 0.0014 & 0.0045 & 3.1761 \\
\hline C2-C3 (C13-C14) & 1.4286 & 1.4451 & 1.4427 & -0.0165 & -0.0140 & 0.8503 \\
\hline C25-C26 (C21-C26) & 1.4295 & 1.4190 & 1.4230 & 0.0105 & 0.0065 & 0.6210 \\
\hline N54-C45 (N53-C30) & 1.4393 & 1.4415 & 1.4417 & -0.0021 & -0.0024 & 1.1268 \\
\hline \multirow[t]{2}{*}{$\mathrm{C} 1-\mathrm{C} 15$} & 3.3183 & 3.3455 & 3.3534 & -0.0272 & -0.0350 & 1.2894 \\
\hline & \multicolumn{6}{|c|}{ angle } \\
\hline C2-B52-C14 & 129.050 & 129.299 & 129.531 & -0.248 & -0.481 & 1.936 \\
\hline $\begin{array}{c}\text { C2-B52-C26 } \\
(\mathrm{C} 14-\mathrm{B} 52-\mathrm{C} 26)\end{array}$ & 115.475 & 115.351 & 115.234 & 0.124 & 0.240 & 1.936 \\
\hline $\begin{array}{c}\text { C3-N53-C25 } \\
(\mathrm{C} 13-\mathrm{N} 54-\mathrm{C} 21)\end{array}$ & 123.853 & 124.534 & 124.217 & -0.681 & -0.364 & 0.534 \\
\hline \multirow[t]{2}{*}{$\begin{array}{c}\text { C3-N53-C30 } \\
\text { (C13-N54-C45) }\end{array}$} & 118.384 & 117.691 & 117.734 & 0.694 & 0.650 & 0.937 \\
\hline & \multicolumn{6}{|c|}{ dihedral angle } \\
\hline C1-C2-C14-C15 & 22.909 & 19.013 & 18.322 & 3.896 & 4.587 & 1.177 \\
\hline C3-N53-N54-C13 & 14.928 & 12.010 & 11.816 & 2.918 & 3.113 & 1.067 \\
\hline $\begin{array}{c}\text { C3-N53-C30-C31 } \\
\text { (C13-N54-C45-C44) }\end{array}$ & 87.696 & 87.499 & 87.874 & 0.197 & -0.178 & -0.901 \\
\hline
\end{tabular}

Table S4. The structural parameter with optimized structures for each state. Calculated using TD-DFT for $\mathrm{S}_{1}$ state and DFT for $\mathrm{S}_{0}$ and $\mathrm{T}_{1}$ state with M062X/6-31g(d,p). Solvent effect was taken into account using PCM for DCM.

\begin{tabular}{|c|c|c|c|c|c|c|}
\hline \multirow{2}{*}{$M 062 X / 6-31 g(d, p)$} & $\mathrm{S}_{0}$ & $\mathrm{~S}_{1}$ & $\mathrm{~T}_{1}$ & $\Delta\left(\mathrm{S}_{1}-\mathrm{S}_{0}\right)$ & $\Delta\left(\mathrm{T}_{1}-\mathrm{S}_{0}\right)$ & $\Delta\left(\mathrm{T}_{1}-\mathrm{S}_{0}\right) / \Delta\left(\mathrm{S}_{1}-\mathrm{S}_{0}\right)$ \\
\hline & \multicolumn{6}{|c|}{ bond length } \\
\hline B52-C2 (B52-C14) & 1.5459 & 1.5425 & 1.5434 & 0.0034 & 0.0025 & 0.7337 \\
\hline B52-C26 & 1.5152 & 1.5148 & 1.5137 & 0.0004 & 0.0015 & 3.5952 \\
\hline N53-C3 (N54-C13) & 1.4000 & 1.4039 & 1.4175 & -0.0039 & -0.0175 & 4.5026 \\
\hline N53-C25 (N54-C21) & 1.3955 & 1.3949 & 1.3876 & 0.0006 & 0.0079 & 12.3281 \\
\hline C2-C3 (C13-C14) & 1.4180 & 1.4349 & 1.4307 & -0.0169 & -0.0126 & 0.7478 \\
\hline $\mathrm{C} 25-\mathrm{C} 26(\mathrm{C} 21-\mathrm{C} 26)$ & 1.4185 & 1.4114 & 1.4131 & 0.0071 & 0.0053 & 0.7567 \\
\hline N54-C45 (N53-C30) & 1.4372 & 1.4398 & 1.4399 & -0.0026 & -0.0027 & 1.0227 \\
\hline \multirow[t]{2}{*}{$\mathrm{C} 1-\mathrm{C} 15$} & 3.3223 & 3.3561 & 3.3698 & -0.0338 & -0.0475 & 1.4054 \\
\hline & \multicolumn{6}{|c|}{ angle } \\
\hline C2-B52-C14 & 129.120 & 129.313 & 129.791 & -0.193 & -0.671 & 3.481 \\
\hline $\begin{array}{c}\text { C2-B52-C26 } \\
(\mathrm{C} 14-\mathrm{B} 52-\mathrm{C} 26)\end{array}$ & 115.440 & 115.344 & 115.105 & 0.096 & 0.336 & 3.480 \\
\hline $\begin{array}{c}\text { C3-N53-C25 } \\
\text { (C13-N54-C21) }\end{array}$ & 124.020 & 124.864 & 124.406 & -0.844 & -0.387 & 0.458 \\
\hline \multirow[t]{2}{*}{$\begin{array}{c}\text { C3-N53-C30 } \\
\text { (C13-N54-C45) }\end{array}$} & 118.262 & 117.584 & 117.557 & 0.678 & 0.705 & 1.039 \\
\hline & \multicolumn{6}{|c|}{ dihedral angle } \\
\hline C1-C2-C14-C15 & 23.193 & 18.991 & 17.909 & 4.202 & 5.284 & 1.257 \\
\hline C3-N53-N54-C13 & 15.135 & 11.538 & 11.475 & 3.597 & 3.660 & 1.017 \\
\hline $\begin{array}{l}\text { C3-N53-C30-C31 } \\
\text { (C13-N54-C45-C44) }\end{array}$ & 87.113 & 87.192 & 87.687 & -0.079 & -0.574 & 7.259 \\
\hline
\end{tabular}


Figure S1-S9

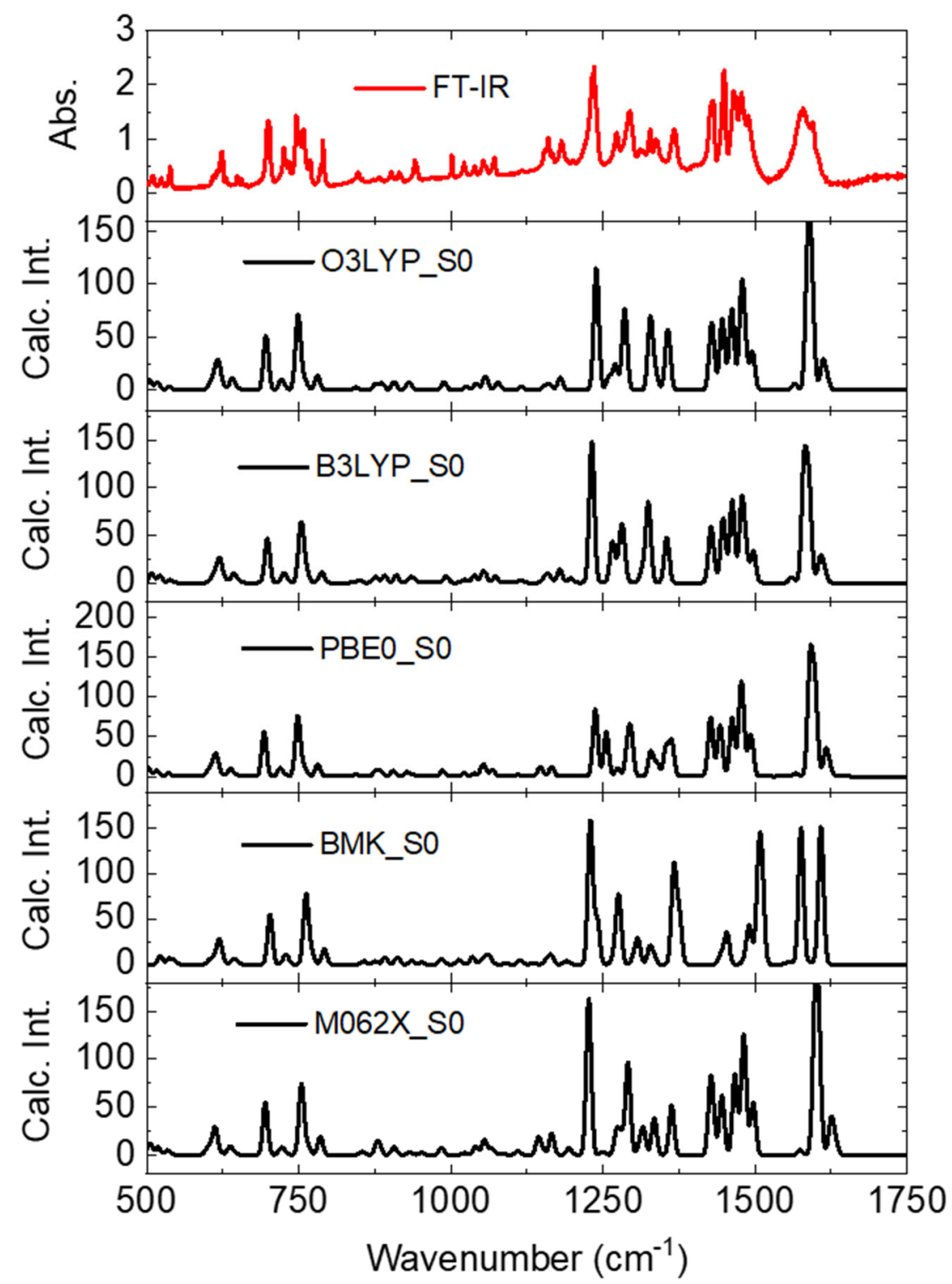

Figure S1. Comparison of FT-IR spectrum (red) and calculated spectra (black). FT-IR spectrum was measured with $\mathrm{KBr}$ pellet. Calculated spectra were obtained with optimized structure by each functional. The scaling factors of 0.975, 0.970, 0.965, 0.980, and 0.965 were adopted for B3LYP, BMK, M062X, O3LYP, and PBE0 functionals, respectively. 


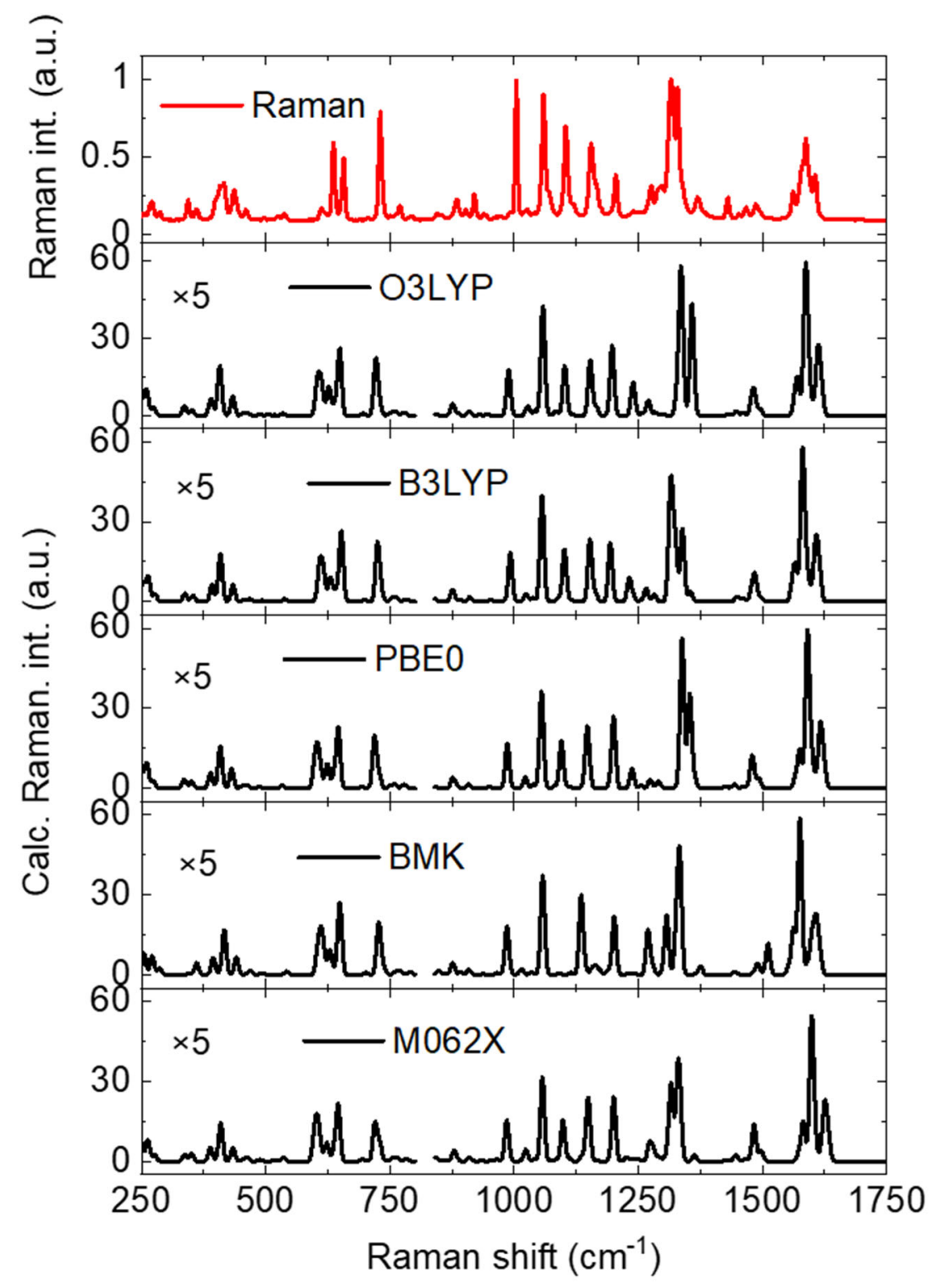

Figure S2. Comparison of Raman spectrum (red) and calculated spectra (black). Raman spectrum was measured with powder samples. Calculated spectra were obtained with optimized structure by each functional. The scaling factors of $0.975,0.970,0.965,0.980$, and 0.965 were adopted for B3LYP, BMK, M062X, O3LYP, and PBE0 functionals, respectively. For calculated spectra, the regions below $800 \mathrm{~cm}^{-1}$ were multiplied by 5 for visibility. 


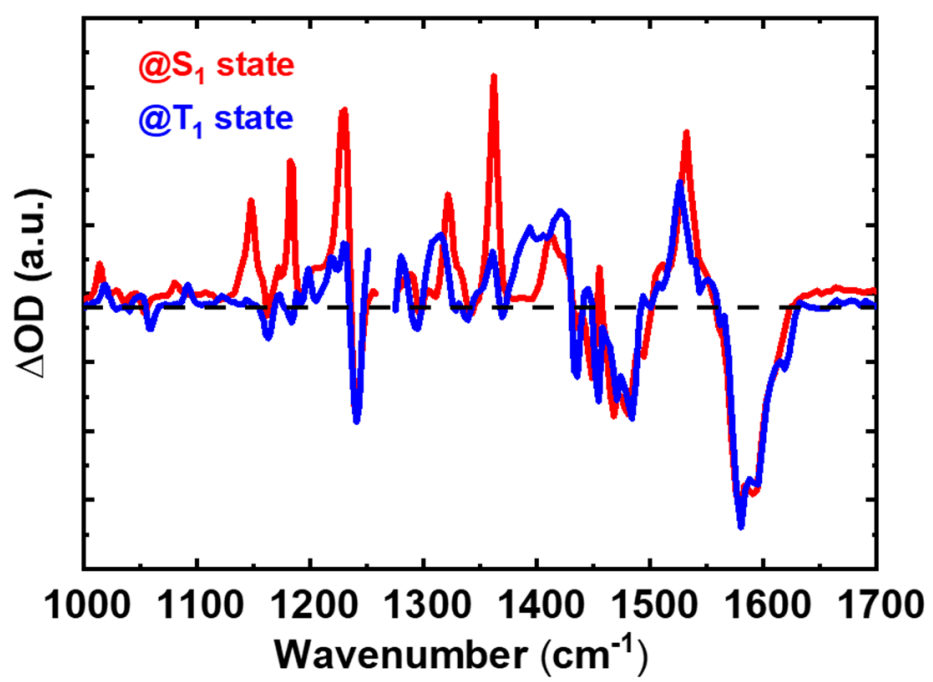

Figure $S 3$. Comparison of TR-IR spectra at $S_{1}$ and $T_{1}$ states. The spectrum at $S_{1}$ and $T_{1}$ states was recorded at 1 ns and 50 ns after photoexcitation with $440 \mathrm{~nm}$, respectively. 


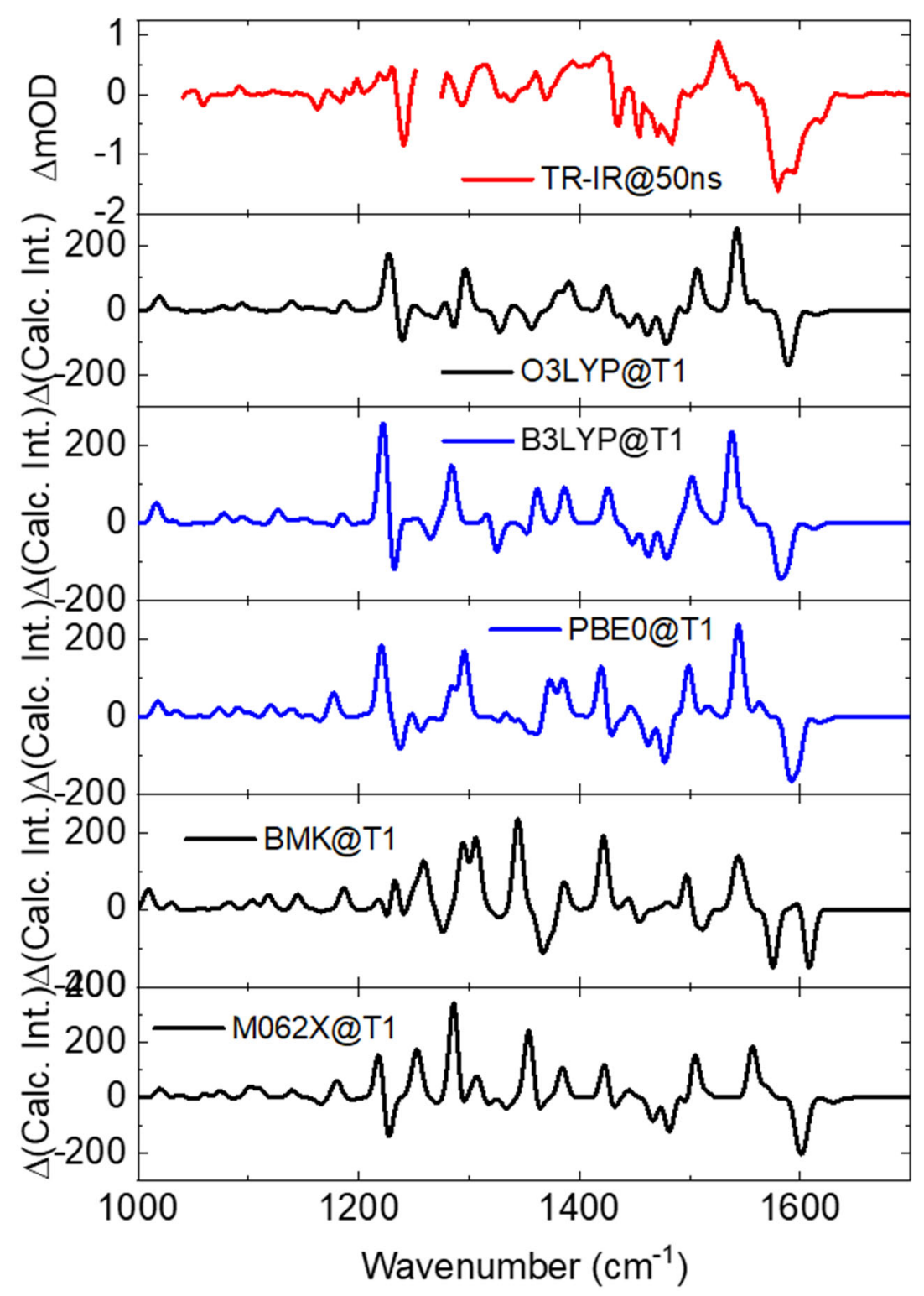

Figure S4. Dependence on the choice of functional for calculated spectrum in $T_{1}$ state. The basis set was 6-31g(d,p) in each case. Solvent effect was taken into account using PCM for DCM. 
(a) $\mathrm{S}_{1}$

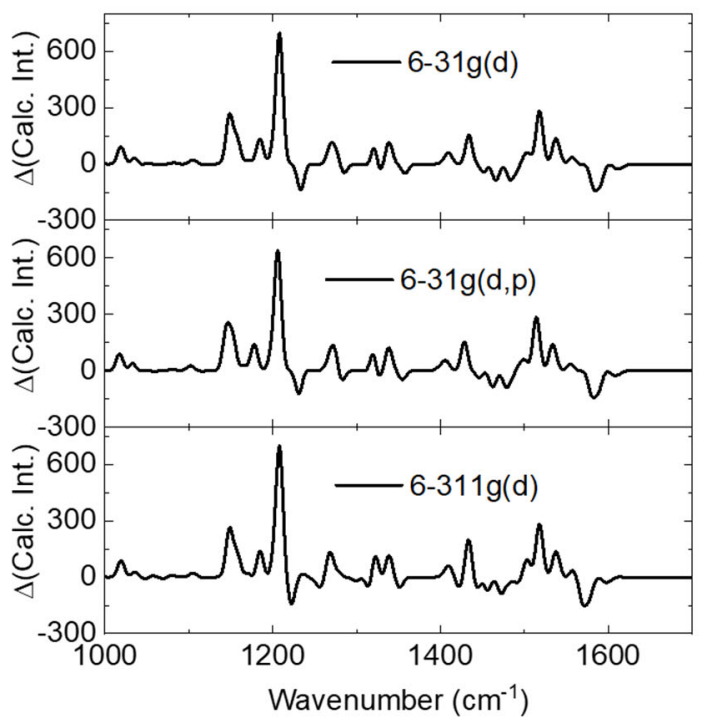

(b) $T_{1}$

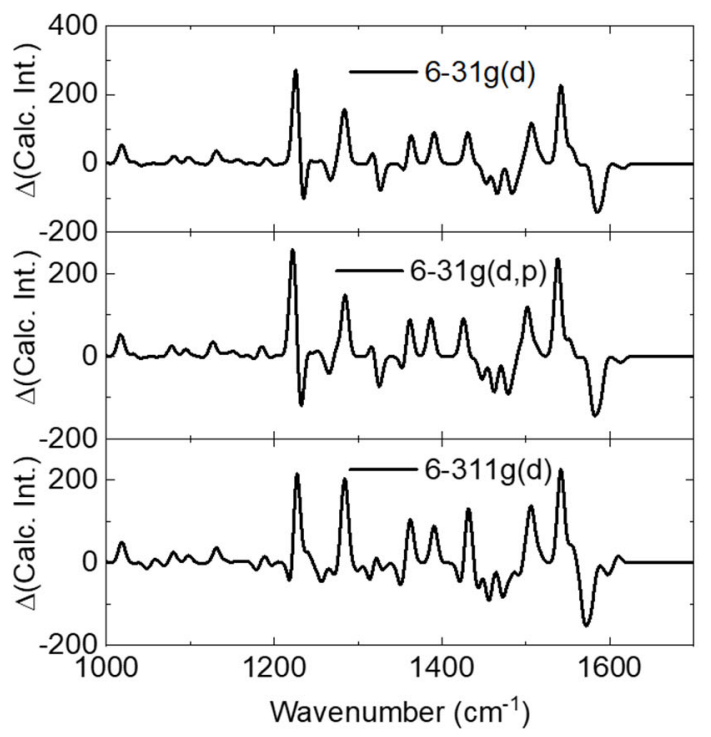

Figure S5. Dependence on the choice of basis set for calculated spectrum in (a) $S_{1}$ and (b) $T_{1}$ state. The B3LYP functional was used in each case. Solvent effect was taken into account using PCM for DCM. 


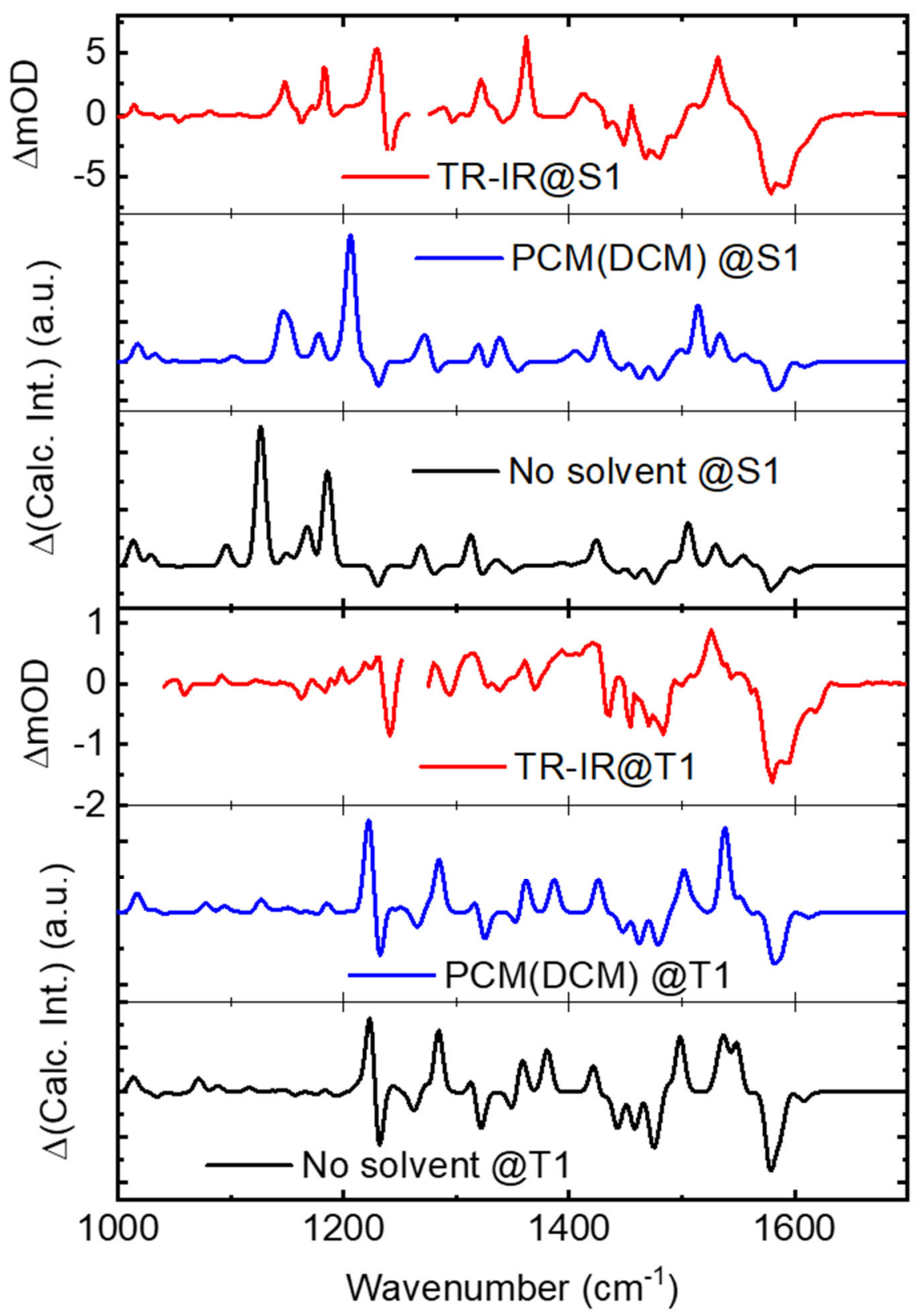

Figure S6. Dependence on the presence(blue)/absence(black) of solvent effects for $\mathrm{S}_{1}$ (upper) and $\mathrm{T}_{1}$ state (lower) in the quantum chemical calculations. The functional and basis set was B3LYP/6-31G(d,p) in each case. We tested the solvent effects of using the PCM of the solvent DCM. TR-IR spectra are shown in red for comparison. 


$$
\begin{array}{llll}
1282 \mathrm{~cm}^{-1} \text { (calc.) } & 1301 \mathrm{~cm}^{-1} \text { (calc.) } & 1343 \mathrm{~cm}^{-1} \text { (calc.) } & 1377 \mathrm{~cm}^{-1} \text { (calc.) } \\
1237 \mathrm{~cm}^{-1} \text { (scaled) } & 1255 \mathrm{~cm}^{-1} \text { (scaled) } & 1296 \mathrm{~cm}^{-1} \text { (scaled) } & 1328 \mathrm{~cm}^{-1} \text { (scaled) }
\end{array}
$$
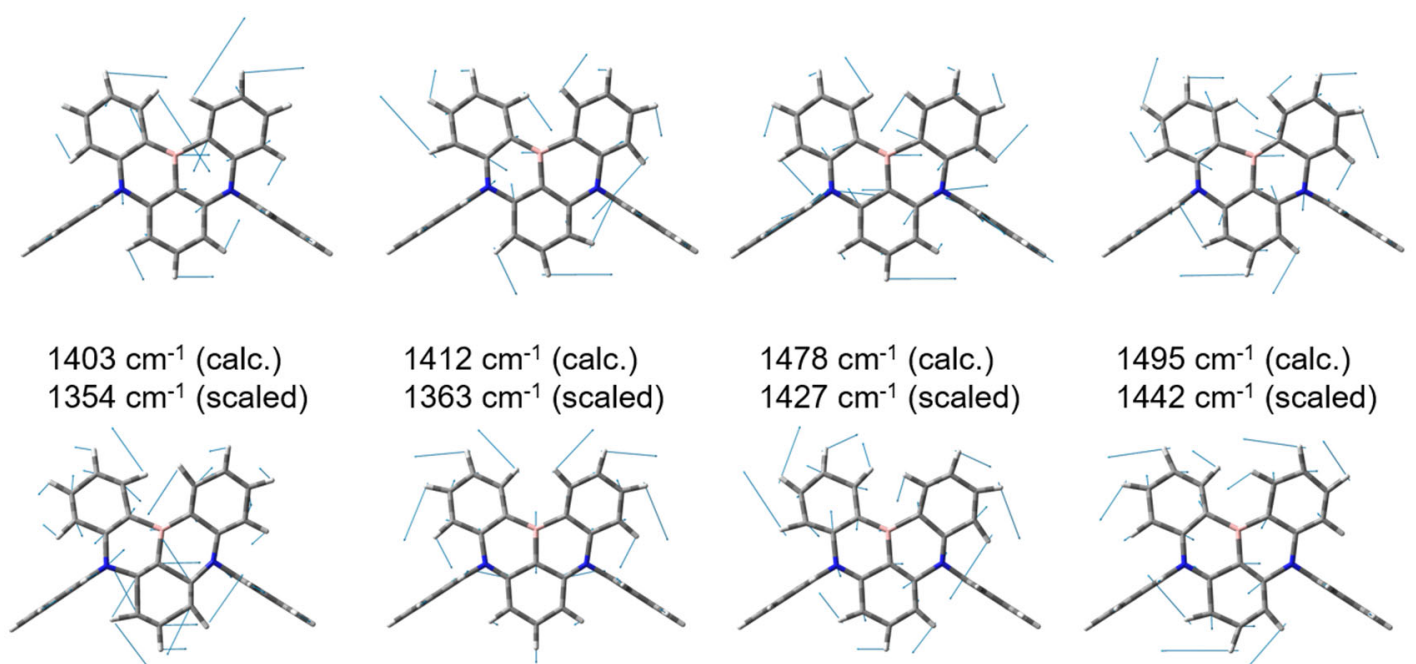

$$
\begin{aligned}
& 1478 \mathrm{~cm}^{-1} \text { (calc.) } \\
& 1427 \mathrm{~cm}^{-1} \text { (scaled) }
\end{aligned}
$$

$$
\begin{aligned}
& 1495 \mathrm{~cm}^{-1} \text { (calc.) } \\
& 1442 \mathrm{~cm}^{-1} \text { (scaled) }
\end{aligned}
$$
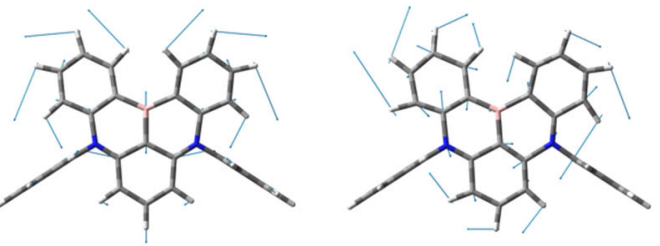

$$
\begin{aligned}
& 1515 \mathrm{~cm}^{-1} \text { (calc.) } \\
& 1462 \mathrm{~cm}^{-1} \text { (scaled) }
\end{aligned}
$$

$1530 \mathrm{~cm}^{-1}$ (calc.) $1477 \mathrm{~cm}^{-1}$ (scaled)

$$
\begin{aligned}
& 1648 \mathrm{~cm}^{-1} \text { (calc.) } \\
& 1590 \mathrm{~cm}^{-1} \text { (scaled) }
\end{aligned}
$$
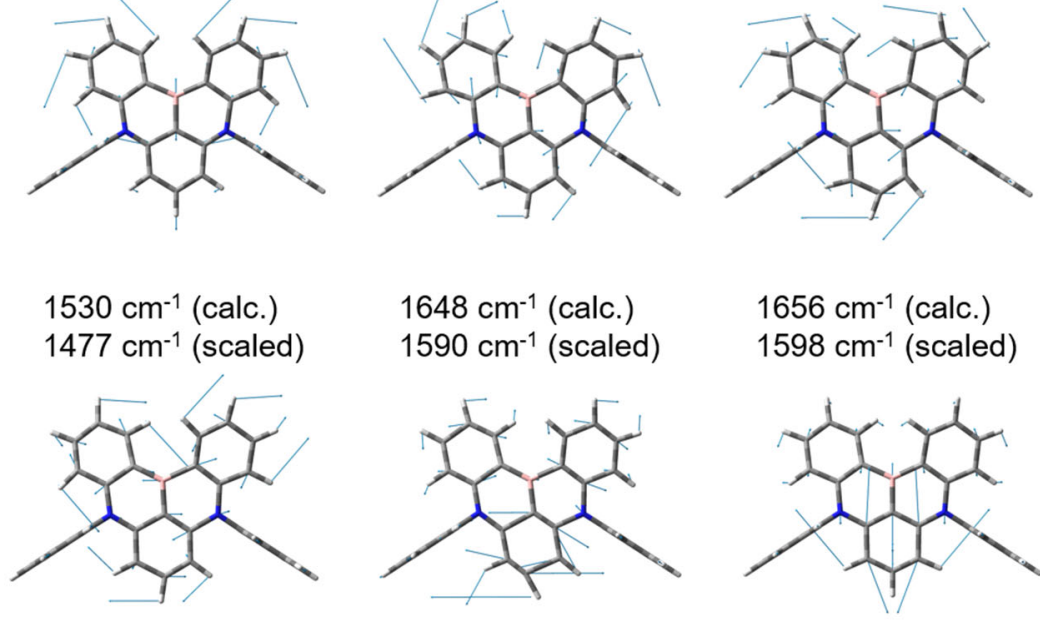

$$
1656 \mathrm{~cm}^{-1} \text { (calc.) }
$$
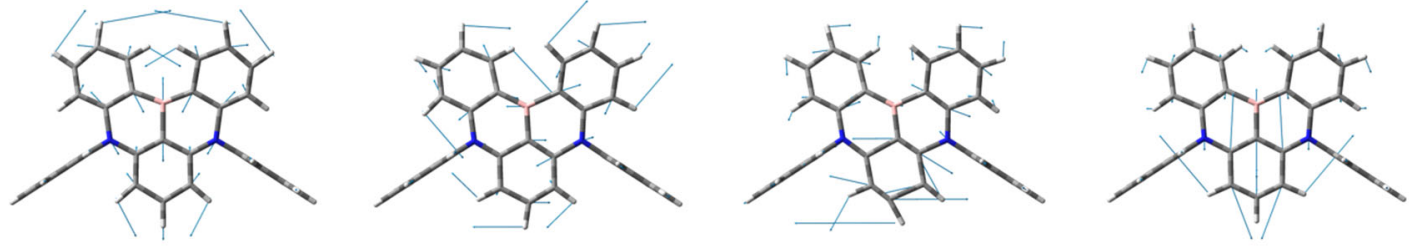

Figure S7. Vibrational assignment of DABNA-1 in $\mathrm{S}_{0}$ state. Calculated with PBE0/6-31g(d,p) level. Solvent effect was taken into account using PCM for DCM. The scaling factors of 0.965 were adopted. 


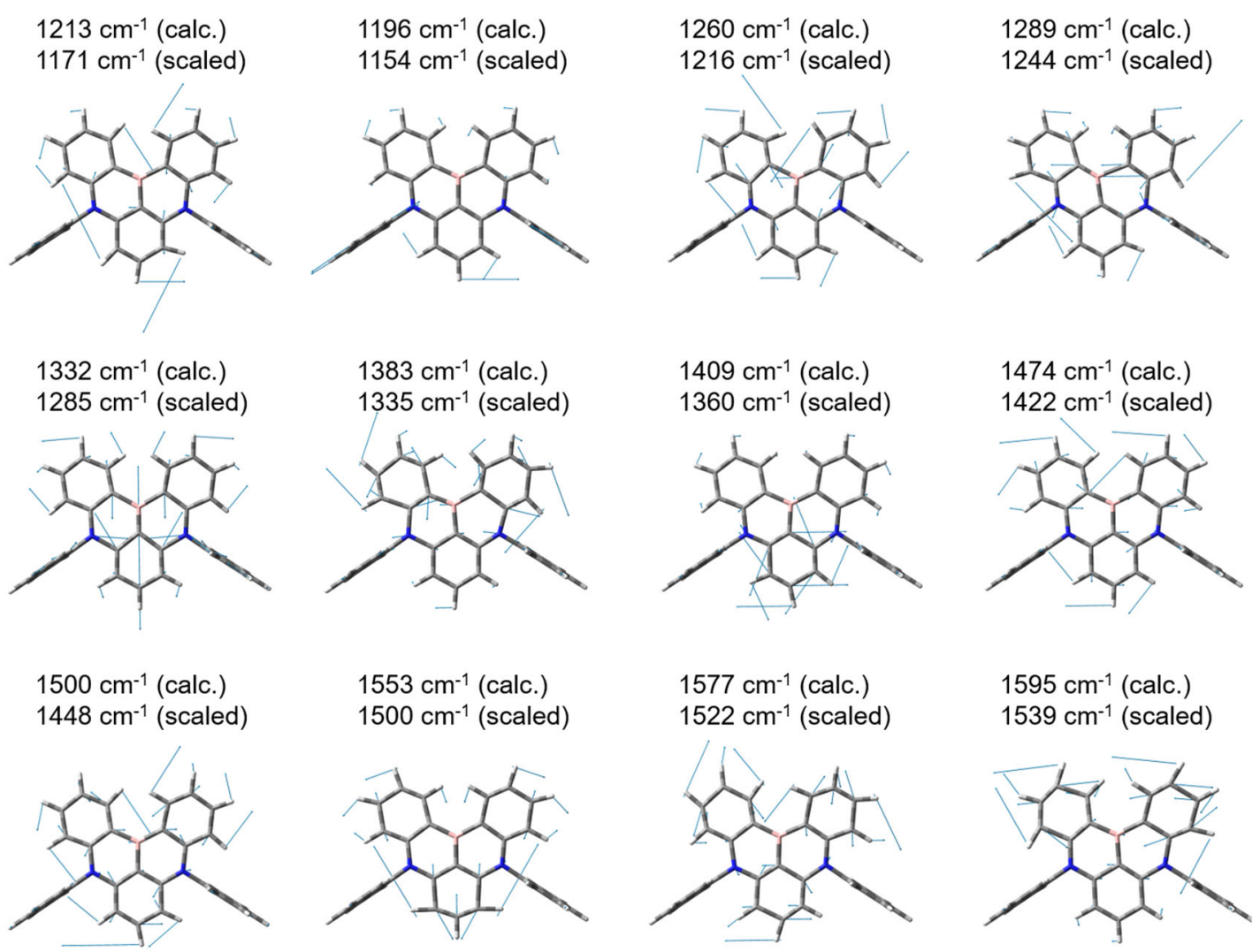

Figure S8. Vibrational assignment of DABNA-1 in $\mathrm{S}_{1}$ state. Calculated with TD-PBE0/6-31g $(\mathrm{d}, \mathrm{p})$ level. Solvent effect was taken into account using PCM for DCM. The scaling factors of 0.965 were adopted. 


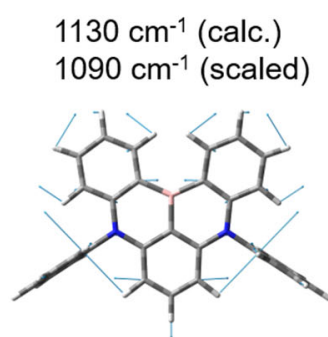

$1381 \mathrm{~cm}^{-1}$ (calc.) $1333 \mathrm{~cm}^{-1}$ (scaled)

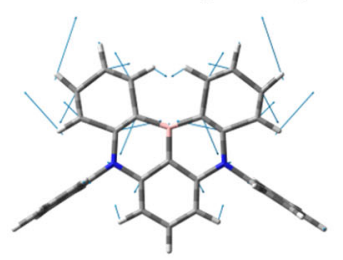

$1472 \mathrm{~cm}^{-1}$ (calc.) $1420 \mathrm{~cm}^{-1}$ (scaled)

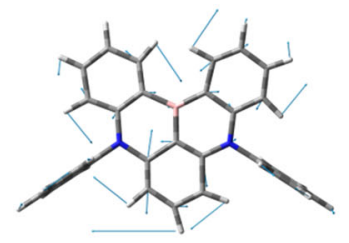

$1220 \mathrm{~cm}^{-1}$ (calc.)

$1177 \mathrm{~cm}^{-1}$ (scaled)

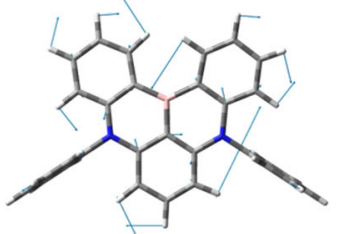

$1381 \mathrm{~cm}^{-1}$ (calc.)

$1333 \mathrm{~cm}^{-1}$ (scaled)

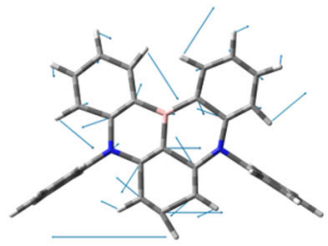

$1553 \mathrm{~cm}^{-1}$ (calc.)

$1498 \mathrm{~cm}^{-1}$ (scaled)

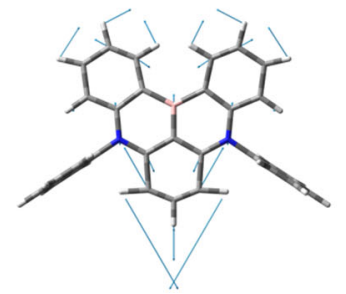

$1265 \mathrm{~cm}^{-1}$ (calc.)

$1221 \mathrm{~cm}^{-1}$ (scaled)

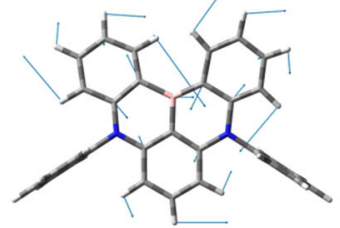

$1436 \mathrm{~cm}^{-1}$ (calc.)

$1385 \mathrm{~cm}^{-1}$ (scaled)

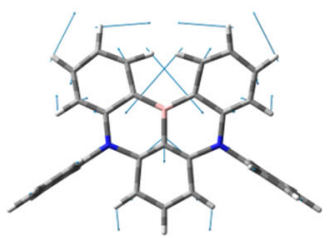

$1553 \mathrm{~cm}^{-1}$ (calc.) $1498 \mathrm{~cm}^{-1}$ (scaled)

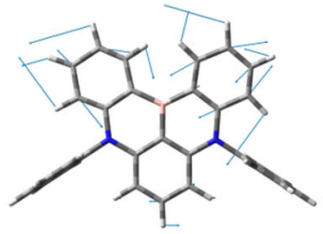

$1343 \mathrm{~cm}^{-1}$ (calc.)

$1296 \mathrm{~cm}^{-1}$ (scaled)

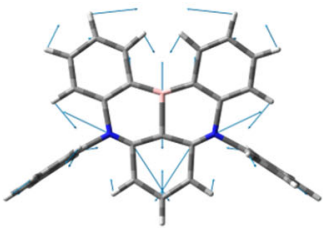

$1472 \mathrm{~cm}^{-1}$ (calc.)

$1420 \mathrm{~cm}^{-1}$ (scaled)

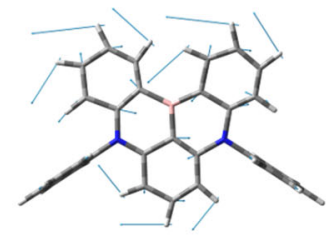

$1553 \mathrm{~cm}^{-1}$ (calc.) $1498 \mathrm{~cm}^{-1}$ (scaled)

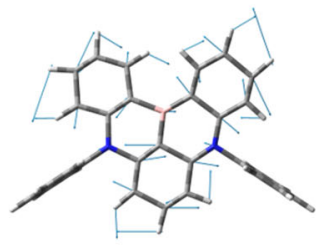

Figure S9. Vibrational assignment of DABNA-1 in $\mathrm{T}_{1}$ state. Calculated with PBE0/6-31g(d,p) level. Solvent effect was taken into account using PCM for DCM. The scaling factors of 0.965 were adopted. 